International Review of Research in Open and Distributed Learning Volume 20, Number 3

July - 2019

\title{
Editorial - Volume 20, Issue 3
}

Dietmar Kennepohl

Interim Co-editor, Athabasca University

Welcome to the third issue of 2019. I hope you are having a good summer. For many, this is not only a time of new ideas and sharing at conferences, but also a chance to step back a moment from the regular mayhem to reflect.

Here at IRRODL we are also taking some time now for self-examination. You will have noticed that as of May 1, 2019 we took a break from accepting submissions (not more than six months) and will be moving to a regularized publication schedule in 2020. As part of our break we are not only catching up on the long publication queue but are also discussing internal processes to improve our focus, balance of topics, and shorten the time from submission to publication.

In a short span of time IRRODL has grown tremendously in popularity, while earning a reputation for high-quality articles. In part, this is because of hard working and dedicated staff supporting the journal. However, I believe our success is primarily due to the ongoing contributions of scholars, and the time and expertise of our reviewers. The value of that community of peer reviewers cannot be overstated. Still, success for IRRODL has also meant dealing with about 600 submissions each year. It is a good problem to have, but still requires careful consideration as to how to best deal with this given our limited resources.

In the meantime, for your own reflections and summertime reading we offer an issue which provides some interesting ideas as well as inspiration.

In our first article Lin presents us with a study of undergraduate students' perceptions of using only OER in an introductory course at a large American public university. Advantages and challenges are identified and used to inform course design and implementation.

In the following paper Mittelmeier, Rogaten, Long, Dalu, Gunter, Prinsloo, and Rienties unpack the early multifaceted adjustments associated with studying in absence of a physical campus in the South African context. Key factors that impact distance learning experiences for students in this regional hub environment are identified and analyzed.

To address low completion rates in MOOCs Handoko, Gronseth, McNeil, Bonk, and Robin compare the differences in the use of self-regulated learning strategies between learners who finished their course and those who did not. While goal setting had the greatest influence on completion, the role of other subprocesses are also examined. 
In their paper, Montes-Rodríguez, Martínez-Rodríguez, and Ocaña-Fernández investigate the prevalence and characteristics of the case study as a methodology for research on MOOCs. A systematic analysis of current scientific literature is presented, eventually building a case for future research using this methodology.

Subramaniam, Suhaimi, Latif, Kassim, and Fadzil explore the factors that could influence readiness levels and indicate that self-efficacy was the most significant. This paper depends on an analysis of adult students studying in Malaysian higher education institutions.

To enhance teachers' continuing professional learning opportunities, Oddone, Hughes, and Lupton propose a model of learning based, in part, on interaction with others through a personal learning network (PLN) underpinned by concepts such as connectivism. The model comprises three elements: arenas of learning, teacher as learner, and PLN.

Al-Samarraie conducts a review of the literature to increase current knowledge regarding the use of videoconferencing systems. A classification of the videoconferencing paradigms from the constructivism and cognitivism perspectives is provided, as well as consideration of relevant challenges that emerge when using certain videoconferencing systems in both learning and teaching situations.

While there are current valid models in the research on adoption of learning technologies, they have a moderate impact on the intention to adopt m-learning among Colombian university students. Indeed, Gómez-Ramirez, Valencia-Arias, and Duque show perceived usefulness and attitude actually have a significant influence on students' acceptance of m-learning and propose an extended model to provide a more complete description.

The next paper considers the perennial and very serious problem of dropout rates for learners in distance education. Brubacher and Silinda show in their study that intrinsic motivation was a significant predictor of persistence, while competence was not.

In this next study, Kimmons, Hunsaker, J ones, and Stauffer analyze website home page system and service data for all available K-12 schools' institutional websites $(n=65,899)$ in the United States. They provide descriptive results of system and service adoption, as well as ascertaining any differences based upon school demographics and service/ system type.

Soffer, Kahan, and Nachmias examine the ways students make use of the flexibility available in online academic courses. They investigate how those patterns might relate to course achievement.

Babori1, Zaid, and Fassi conducted a review of the literature covering MOOCs in major refereed journals, produced mainly between 2012 and 2018. The synthesis presented here concentrates on these studies and aims to examine the place held by content.

We also have two book reviews in this issue. First, Chen, Chen, Fang, and Zhou look at Best Practices for Flipping the College Classroom (Waldrop and Bowdon, Eds.) which is "a noteworthy contribution to the field and is likely to inspire early adopters in terms of further exploration and implementation." Second, Saykili determines that the work "offers a renewed lens toward understanding the complexity of 
higher education today" in his evaluation of Transactional Distance and Adaptive Learning: Planning for the Future of Higher Education (by Saba and Shearer).

We conclude the issue with a couple of Notes from the Field. First, given the substantive number of employees in the health care and social services sector who are seeking continuing education as part of their profession Colley, Schouten, Chabot, Downs, Anstey, Moulin, and Martin initiated a study sought to identify and characterize online graduate programs in health sciences offered by Canadian universities. Finally, Baldwin and Ching provide an excellent review of the characteristics and unique features of a newly released course evaluation instrument from the popular learning management system Canvas.

Enjoy!

\section{Athabasca} University

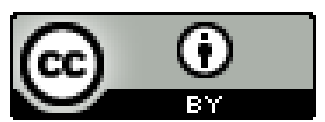

